\title{
Modeled Antarctic Precipitation. Part II: ENSO Modulation over West Antarctica*
}

\author{
ZHICHANG GuO ${ }^{+}$AND DAVID H. BROMWICH \\ Polar Meteorology Group, Byrd Polar Research Center, and Atmospheric Sciences Program, Department of Geography, \\ The Ohio State University, Columbus, Ohio \\ KeITH M. HINES \\ Polar Meteorology Group, Byrd Polar Research Center, The Ohio State University, Columbus, Ohio
}

(Manuscript received 24 October 2002, in final form 10 June 2003)

ABSTRACT

The impacts of the El Niño-Southern Oscillation (ENSO) on the Antarctic region are of special importance in evaluating the variability and change of the climate system in high southern latitudes. In this study, the ENSO signal in modeled precipitation over West Antarctica since 1979 is evaluated using forecast precipitation from several meteorological analyses and reanalyses. Additionally, a dynamical retrieval method (DRM) for precipitation is applied. Over the last two decades, the Southern Oscillation index (SOI) has an overall anticorrelation with precipitation over the West Antarctic sector bounded by $75^{\circ}-90^{\circ} \mathrm{S}, 120^{\circ} \mathrm{W}-180^{\circ}$ while it is positively correlated with precipitation over the South Atlantic sector bounded by $65^{\circ}-75^{\circ} \mathrm{S}, 30^{\circ}-60^{\circ} \mathrm{W}$.

Decadal variations are found as the relationship between the SOI and West Antarctic precipitation is stronger in the 1990s than that in the 1980s. The polar front jet stream, West Antarctic precipitation, and the SOI show a well-ordered correspondence during the 1990s as the jet zonal speed is negatively correlated to the SOI and positively correlated to West Antarctic precipitation. These relationships are weaker during the 1980s, consistent with the change in sign of the correlation between the SOI and West Antarctic precipitation. The decadal variations are apparently related to changes in the quasi-stationary eddies that determine the local onshore and offshore flow over West Antarctica.

\section{Introduction}

The El Niño-Southern Oscillation (ENSO) is recognized as one of the most prominent sources of global climate variability. Not only have its signatures been found in tropical areas, but they are also found in remote parts of the globe. Over Antarctica and the surrounding oceans signals are present in the surface temperature and pressure (Smith and Stearns 1993), the tropospheric split jet (Chen et al. 1996), sea ice (Carleton 1988; Gloersen 1995; Simmonds and Jacka 1995; Yuan and Martinson 2000; Kwok and Comiso 2002), and precipitation/accumulation in a sector $\left(75^{\circ}-90^{\circ} \mathrm{S}, 120^{\circ} \mathrm{W}-\right.$ $180^{\circ}$ ) of West Antarctica (Fig. 1, Cullather et al. 1996; Bromwich et al. 2000).

Among these findings, particular interest has focused on the ENSO signal in West Antarctic precipitation for

\footnotetext{
* Byrd Polar Research Center Contribution Number 1283.

+ Current affiliation: Center for Ocean-Land-Atmosphere Studies, Calverton, Maryland.
}

Corresponding author address: David H. Bromwich, Polar Meteorology Group, Byrd Polar Research Center, The Ohio State University, 1090 Carmack Rd., Columbus, OH 43210-1002.

E-mail: bromwich@polarmet1.mps.ohio-state.edu the following reasons. First, the Ross Sea area in the West Antarctic sector has been found to be one of pivotal significance for global climate variability and change, and it is critical in the transport of mass, heat, and momentum between the Antarctic continent and middle latitudes of the Southern Hemisphere on a variety of time scales (e.g., Parish and Bromwich 1998; Hines and Bromwich 2002). Second, over the last 50 years the Antarctic Peninsula and its vicinity have experienced major climatic change as evidenced by rising surface temperature (King 1994; Smith et al. 1996; Hansen et al. 1999) and the disintegration of a number of floating ice shelves (Rott et al. 1998; Scambos et al. 2000). The ENSO signal detection helps examine the role of tropical forcing in such regional climate change. Third, the surface mass balance of polar ice sheets is the net result of the precipitation, sublimation/deposition, drift snow, and melt. Among various components of the surface mass balance, precipitation is the dominant term and is believed to be an important contributor to global sea level change (e.g., Bentley 1993). Fourth, the ENSO signal in precipitation over the West Antarctic sector is still somewhat uncertain due to conflicting findings. As discussed below, precipitation minus evaporation/sublimation $(P-E)$ closely approximates snow accumu- 


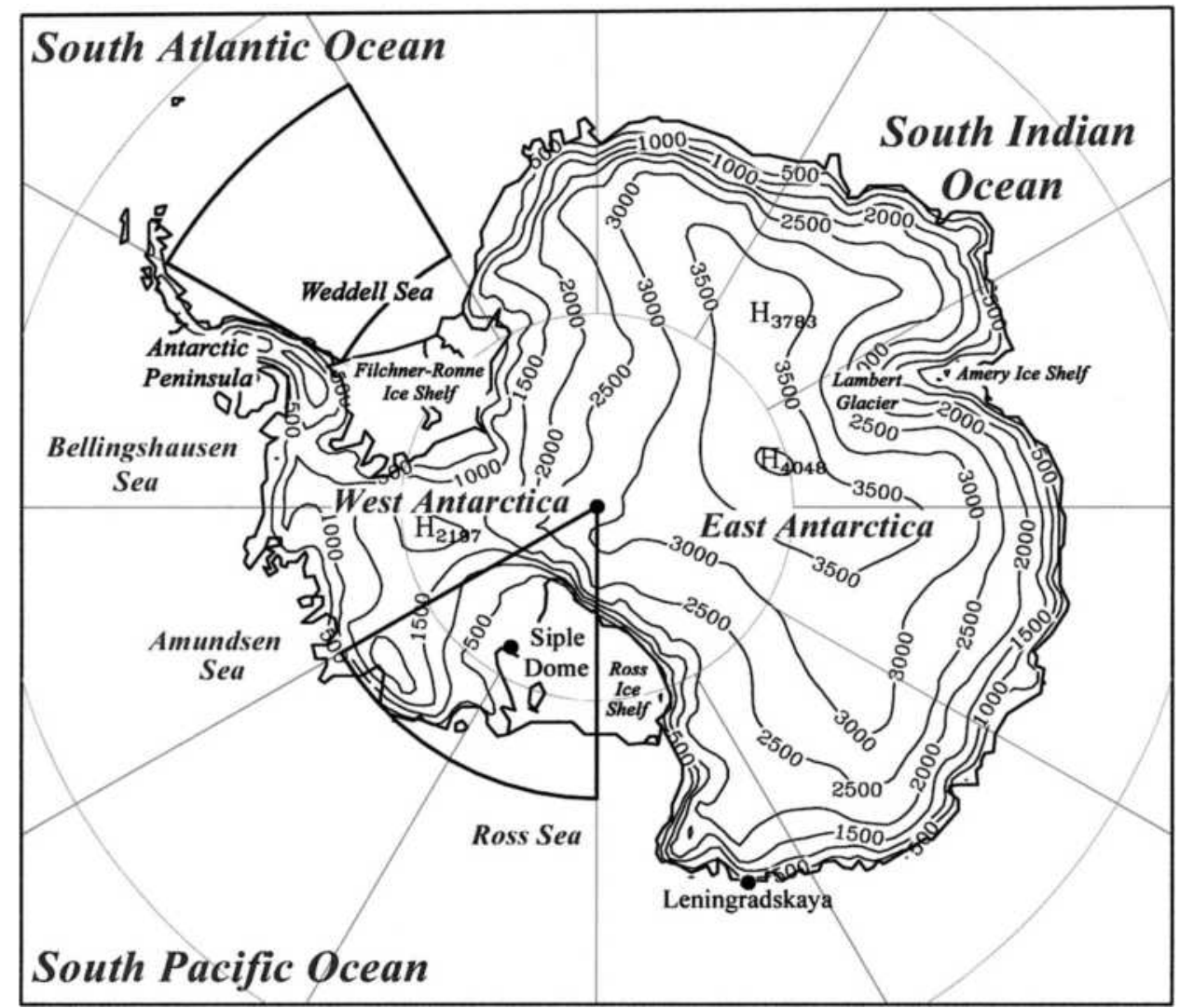

FIG. 1. Map of Antarctica with topographic features and West Antarctic sectors that are of particular interest. Elevation contour interval is $500 \mathrm{~m}$.

lation over the ice sheet interior and the West Antarctic sector. Cullather et al. (1996) and Bromwich et al. (2000) detect a decadally varying ENSO signal in $P-$ $E$ derived from the atmospheric moisture budget using European Centre for Medium-Range Weather Forecasts (ECMWF) Tropical Ocean Global Atmosphere (TOGA) Project operational analyses. They conclude that the relationship between the $P-E$ over the West Antarctic sector and the Southern Oscillation index (SOI) switches abruptly from a positive correlation from the early 1980s until 1990 to a negative correlation after 1990. In contrast, Genthon and Krinner (1998) are unable to find a strong ENSO signal in the modeled West Antarctic precipitation using data from the ECMWF 15-yr Re-Analysis (ERA-15). Finally, as stated by Bromwich et al. (2000), understanding the ENSO teleconnection with high southern latitudes will lead to better seasonal forecasting. The unusually severe weather conditions during the austral summer of 1997/98 (one of the most intense ENSO periods of the last century) encountered by U.S. Antarctic field researchers underline the importance of seasonal forecasting for the Ross Ice Shelf and West Antarctic regions.

The currently available precipitation datasets such as the Global Precipitation Climatology Project Version 2 (GPCP-2) satellite-gauge precipitation dataset (Huff- man et al. 1997) and the Xie-Arkin dataset (Xie and Arkin 1998) are unreliable for studies of West Antarctic precipitation (Bromwich et al. 2004a). Furthermore, direct precipitation and accumulation measurements over the Antarctic are replete with practical difficulties. Here, modeled precipitation data from the following sources are used to detect ENSO signals over the West Antarctic sector: the National Centers for Environmental Prediction (NCEP) Department of Energy (DOE) Atmospheric Model Intercomparison Project 2 (AMIP-2) reanalysis (NCEP2; 1979-2000); ECMWF/TOGA operational analyses (ECT, 1991-2000); ERA-15 (1979-93); and modeled precipitation from the dynamic retrieval method (DRM). Furthermore, a combination called ERA-15/ ECT consists of ERA-15 for 1979-90 and ECT for 1991-99. The use of the DRM to calculate precipitation has been developed and verified for the Greenland ice sheet (Chen et al. 1997; Bromwich et al. 2001). The DRM has also been successfully applied to retrieve the precipitation for Antarctica from 1979 to 1999 using ECT and ERA-15 datasets, as discussed in a parallel paper (Bromwich et al. 2004a). Additionally, the Polar MM5, a regional atmospheric model based on the fifthgeneration Pennsylvania State University-National Center for Atmospheric Research (PSU-NCAR) Mesoscale Model (Bromwich et al. 2004a,b; Guo 2003) 
has been run over Antarctica for July 1996-June 1999, and the interannual variability of simulated precipitation, sublimation, and $P-E$ are evaluated over the West Antarctic sector in comparison with the SOI.

Recently, some errors have been found in several of the above datasets (e.g., Bromwich et al. 2000; Hines et al. 2000; Marshall and Harangozo 2000; Kanamitsu et al. 2002; Marshall 2002). In this study, modeled precipitation and reanalyses data from various sources are used in order to alleviate the uncertainty associated with the study of any one dataset. Noting the close relationship between the interannual variability in precipitation and mean circulation (Bromwich et al. 2000), we also study the correlation between the modeled West Antarctic precipitation and strength of the polar front jet. The polar front jet is the southern component of the tropospheric split jet over the South Pacific Ocean. Over the central Pacific Ocean, the ENSO cycle modulates the jet (Chen et al. 1996).

We evaluate these linkages with correlation studies. To filter out annual cycles while preserving interannual variability, 12-month centered running means are first applied to the data. Additionally, correlations have been calculated between the annual mean (May-April) values to verify the results. The detection of ENSO signals in the precipitation over West Antarctica is presented in section 2. The linkage between the polar front jet stream and precipitation over the West Antarctic sector is presented in section 3. Finally, a summary of the findings is given in section 4 .

\section{Detection of ENSO variability of modeled precipitation over West Antarctica}

The DRM is discussed in Bromwich et al. (2004a, hereafter Part I). This method uses the association between the vertical motion and large-scale condensation to retrieve the precipitation. In comparison to atmospheric models, the dynamic retrieval method has the advantages that no initialization or parameterizations of the complex physical processes are necessary in the retrieval process, and associated errors in parameterizations and model spinups are reduced. These advantages make the retrieval method compelling for detection of ENSO signals in retrieved precipitation over West Antarctica. To retrieve the precipitation with the DRM, a square polar stereographic domain centered at the South Pole is employed for the calculations. The horizontal domain consists of 181 grid points in each orthogonal direction with a resolution of $40 \mathrm{~km}$. The model topography data over the Antarctic continent are interpolated from a 5-km-resolution digital elevation model of Antarctica (Liu et al. 1999) using bilinear interpolation from the nearest points (Fig. 1).

Previously, the ENSO modulation of Antarctic accumulation was evaluated by Bromwich et al. (2000) using moisture flux convergence to estimate $P-E$,

$$
\langle\bar{P}-\bar{E}\rangle=-\frac{1}{A} \oint\left(\int_{0}^{P_{\mathrm{sfc}}} \frac{\overline{q \mathbf{V}}}{g} d p\right) \cdot \mathbf{n} d l,
$$

where $P$ is the precipitation rate, $E$ is the rate of evaporation/sublimation, $A$ is the area over which the net precipitation is calculated, $g$ is gravity, $q$ is specific humidity, $p$ is pressure, $P_{\text {sfc }}$ is the surface pressure, $\mathbf{V}$ is the horizontal velocity, and $\mathbf{n}$ is the outward normal to the area perimeter. Genthon and Krinner (1998) demonstrated that precipitation is much larger than evaporation over Antarctic latitudes, and Guo et al. (2003) show that this is particularly true for the West Antarctic sector. Both of these sources show that the interannual variability of $P-E$ overwhelmingly results from the precipitation. Thus, it is reasonable that we examine the forecast precipitation to further our knowledge on the linkage of $P-E$ variations to ENSO. Furthermore, although the forecast precipitation from analyses and reanalyses should ideally be closely linked to the moisture flux convergence, Genthon and Krinner (1998) found that the ERA-15 forecast $P-E$ is more than $10 \%$ less that derived from the corresponding moisture flux of the analyzed fields for the polar cap inside $70^{\circ} \mathrm{S}$. Given this lack of closure, we do not necessarily expect close agreement between the forecast precipitation and the retrieved precipitation on regional scales.

\section{a. ENSO correlations to precipitation}

Correlation patterns provide an empirical picture of the teleconnections relating temporal variability in the different regions of the world. Figures $2 \mathrm{a}, 3 \mathrm{a}$, and $4 \mathrm{a}$ present 12 -month centered running mean correlations between the SOI and modeled precipitation over high southern latitudes for the last two decades calculated from NCEP2, ERA-15/ECT, and DRM, respectively, while Figs. 2b, 3b, and 4b show their counterparts for the 1990s. Monthly values of the Tahiti-minus-Darwin SOI are obtained from the Climate Prediction Center (more information available online at http://www.cpc. ncep.noaa.gov/data/indices/). In order to show the significance level related to sample amounts in the correlation calculations, different grayscales are used in these figures, and the confidence levels accounting for autocorrelation are indicated with those scale bars. Correlations are generally largest between the SOI and the modeled precipitation at a lag of 0 months. Consequently, no lagged correlations are discussed for simplicity.

Several areas, where the correlation between the SOI and modeled precipitation is statistically significant for the last two decades, especially in the 1990s, clearly stand out in Figs. 2-4. Those areas include the South Atlantic sector near the Weddell Sea, the West Antarctic sector near the Ross and Amundsen Seas, and the Amery Ice Shelf (Fig. 1). Although there are some differences in the details of the correlation patterns, all datasets generally agree with each other in reproducing the basic 

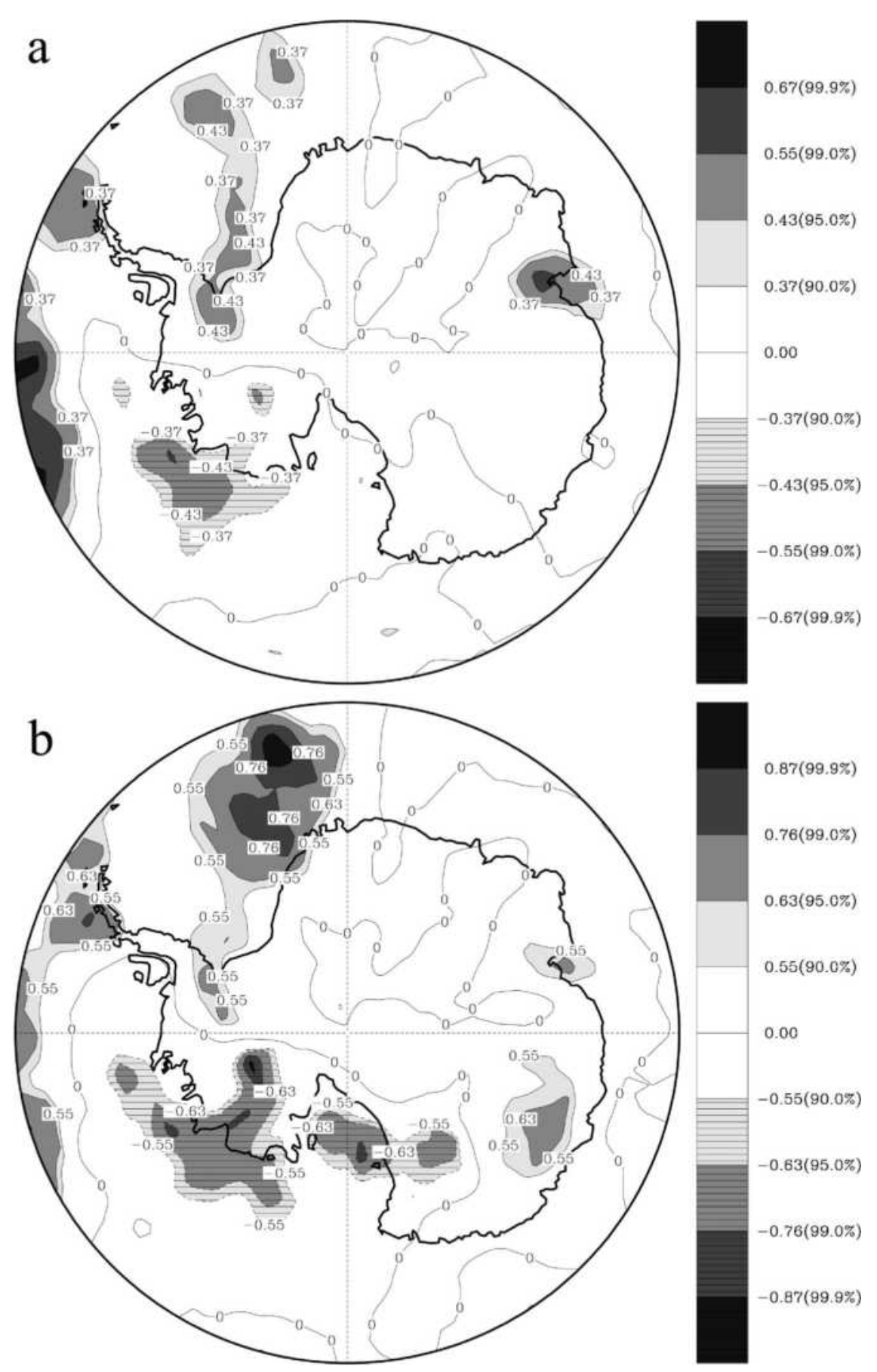

FIG. 2. Map of correlations of 12-month running means between the SOI and forecast precipitation over Antarctica from the NCEP-DOE AMIP-2 reanalysis for (a) 1979-99 and (b) 199099. Shading denotes the confidence of the correlations according to a Student's $t$ test.

features of the spatial distribution. In Figs. 2a, 3a, and 4a significant positive correlations can be found in the South Atlantic sector and Amery Ice Shelf, and a significant negative correlation can be found in a small area in the West Antarctic sector for the last two decades. Those correlations are found to be robust in the 1990s with larger areas and magnitudes than those in the last two decades.

We will focus on the two sectors shown in Fig. 1 for several reasons. The correlations in Figs. 2-4 tend to be large in these areas. The Ross Sea area in the West Antarctic sector is critical in the transport of mass, heat, 

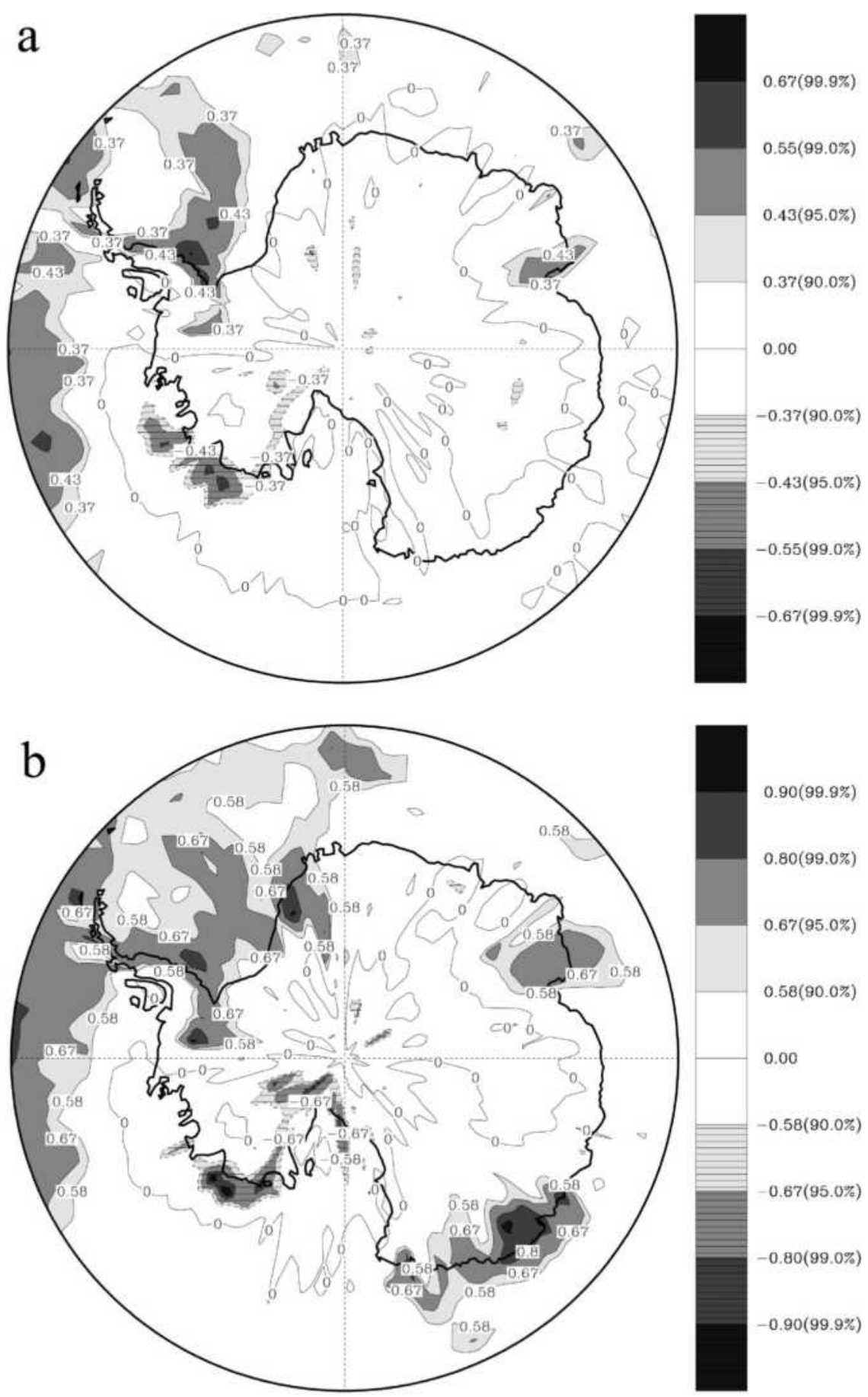

FIG. 3. Map of correlations of 12-month running means between the SOI and forecast precipitation over Antarctica for (a) 1979-99 and (b) 1990-99 from the combined ERA-15 reanalysis (1979-90) and ECMWF analysis (1991-99) datasets.

and momentum between the Antarctic continent and middle latitudes of the Southern Hemisphere on a variety of time scales. The two sectors are near the locations most impacted by the Antarctic dipole, which is strongly modulated by the ENSO cycle (Yuan and Martinson 2001). The dipole ENSO responses in these areas during the late-1990s ENSO cycle is clearly demonstrated by the modeling results with Polar MM5 by Bromwich et al. (2004b). Furthermore, the Weddell Sea sector is close to the Antarctic Peninsula where major climatic change has been observed over the last 50 years. 

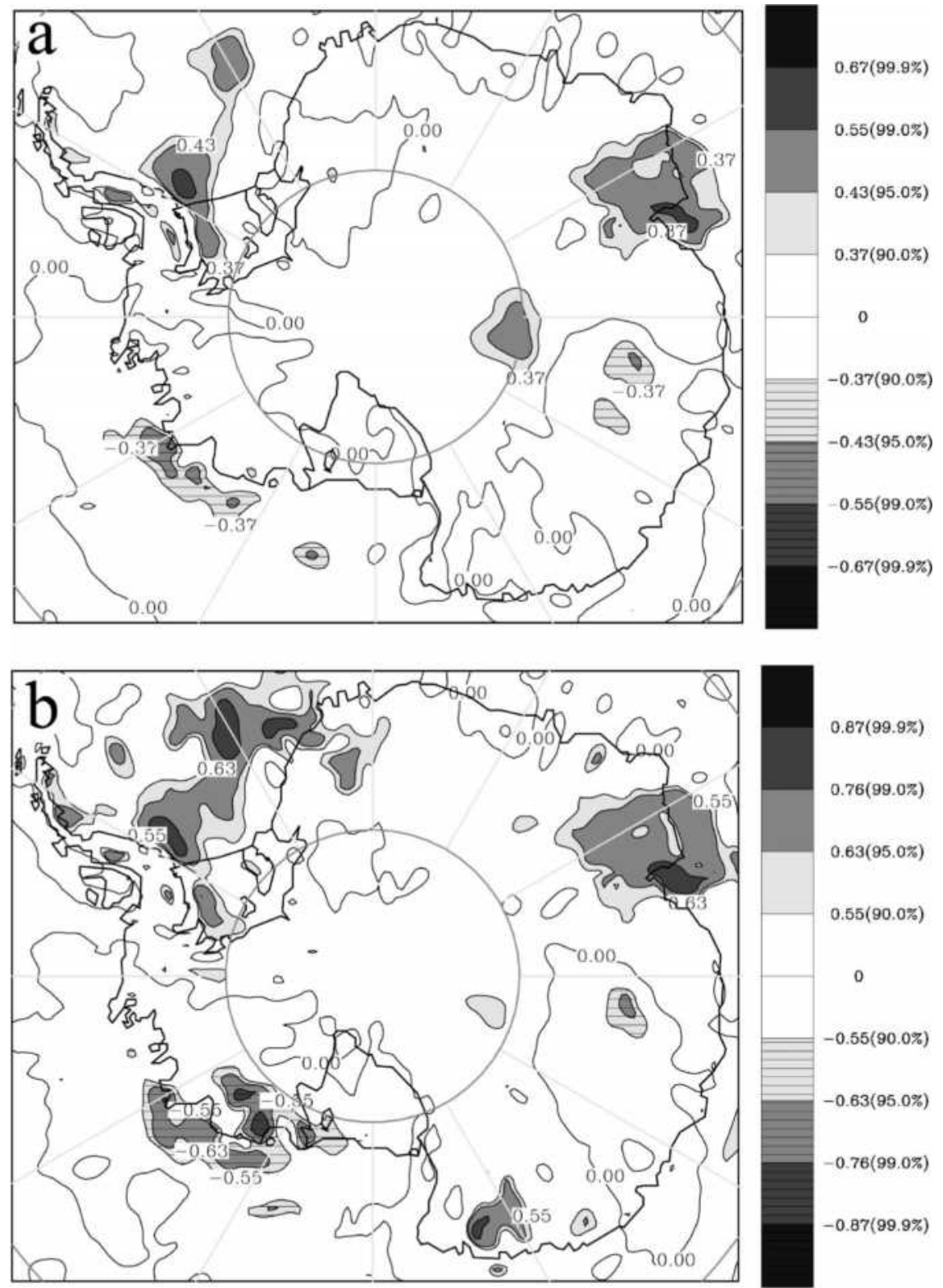

FIG. 4. Map of correlations of 12-month running means between the SOI and modeled precipitation over Antarctica for (a) 1979-99 and (b) 1990-99. Precipitation is retrieved with the dynamic retrieval method from ERA-15 for 1979-89 and ECT for 1990-99.

\section{b. Time series}

Figure 5 shows the monthly mean and annual mean time series for the modeled precipitation over the West Antarctic sector bounded by $75^{\circ}-90^{\circ} \mathrm{S}, 120^{\circ} \mathrm{W}-180^{\circ}$ (Fig. 1). All three datasets agree closely each other in reproducing both the seasonal and interannual variations in mean precipitation averaged over the West Antarctic sector (Fig. 5, Table 1). The correlations among the three datasets in the last two decades are 0.77 and 0.65 or larger for monthly and annual mean values, respectively. Monthly mean and annual mean time series for the modeled precipitation over the South Atlantic sector bound- ed by $65^{\circ}-75^{\circ} \mathrm{S}, 30^{\circ}-60^{\circ} \mathrm{W}$ are shown in Fig. 6 . Interannual variations in precipitation appear to be on the order of $100 \mathrm{~mm} \mathrm{yr}^{-1}$ for this sector, about twice as large as for the West Antarctic/Ross Sea sector. Although precipitation over the South Atlantic sector is significantly underestimated by the dynamic retrieval method due to the omission of mesoscale convection and associated precipitation, a similarly good agreement is found in the seasonal and interannual variations in South Atlantic precipitation from various methods. The correlations among three datasets in the last two decades are larger than 0.80 and 0.63 for monthly and annual 

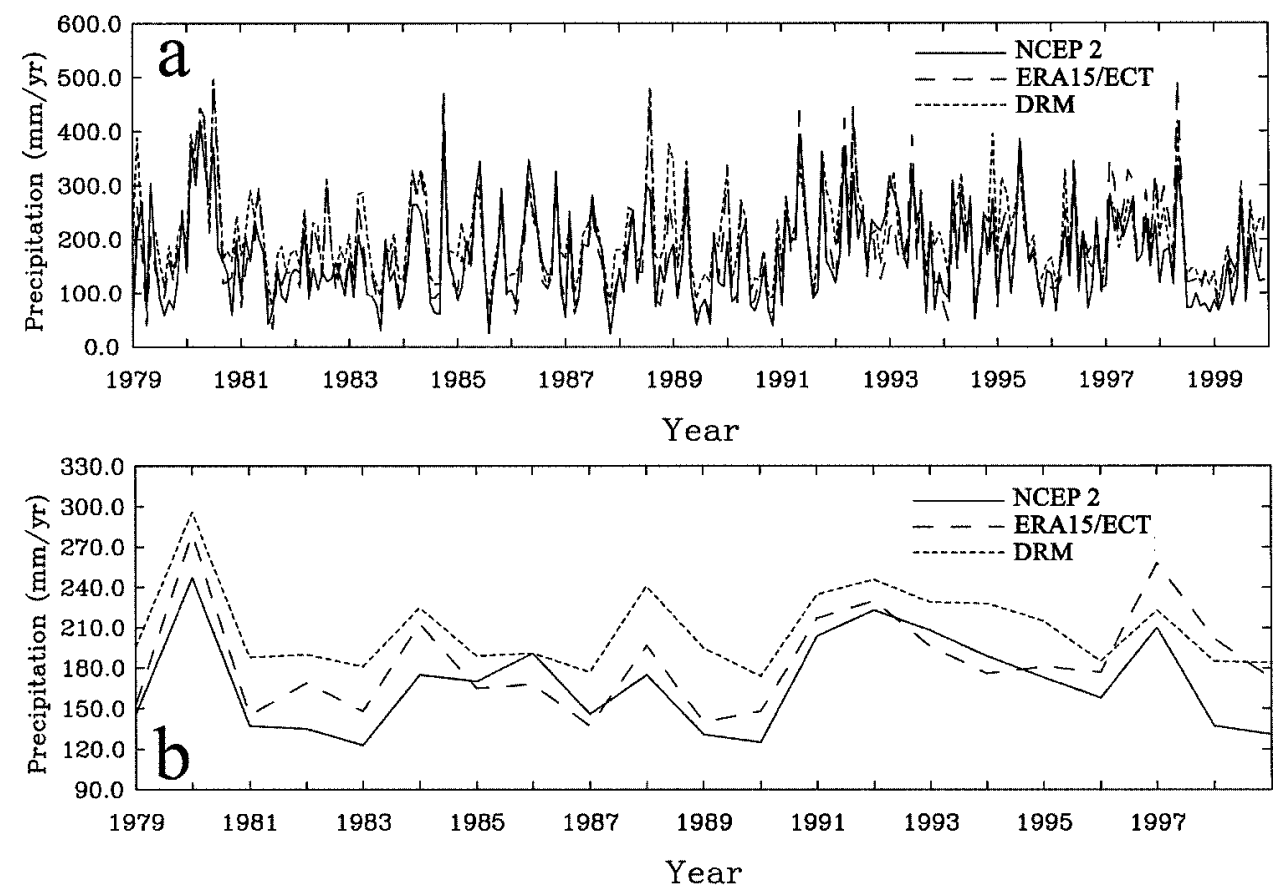

FIG. 5. Time series of the modeled precipitation for (a) monthly means and (b) annual means over the West Antarctic sector bounded by $75^{\circ}-90^{\circ} \mathrm{S}, 120^{\circ} \mathrm{W}-180^{\circ}$.

mean values, respectively. These good agreements in the seasonal and interannual variations suggest that the ENSO signals in the interannual variation of precipitation in these two sectors are strong enough to survive in reproduction by various methods (with different physics configurations).

To examine the regional features of the relationship pattern between the SOI and West Antarctic precipitation, monthly means of modeled precipitation are averaged over two sectors shown in Fig. 1: the West Antarctic sector $\left(75^{\circ}-90^{\circ} \mathrm{S}, 120^{\circ} \mathrm{W}-180^{\circ}\right)$ and the South Atlantic sector $\left(65^{\circ}-75^{\circ} \mathrm{S}, 30^{\circ}-60^{\circ} \mathrm{W}\right)$. Correlations between the area-averaged precipitation and the SOI are then calculated.

Figure 7 a presents 12 -month centered running means of the Southern Oscillation index and modeled precipitation for the West Antarctic sector. During the time period investigated, the ENSO cycle experiences three well-defined cold events (SOI $>$ 0) during 1988/89, 1996, and 1998/99 and three well-defined warm events

TABLE 1. Correlation between different representations of modeled precipitation for 1979-99 over the West Antarctic sector bounded by $75^{\circ}-90^{\circ} \mathrm{S}, 120^{\circ} \mathrm{W}-180^{\circ}$.

\begin{tabular}{lccc}
\hline \hline Modeled precipitation & $\begin{array}{c}\text { Monthly } \\
\text { mean }\end{array}$ & $\begin{array}{c}\text { 12-month } \\
\text { running mean }\end{array}$ & $\begin{array}{c}\text { Annual } \\
\text { mean }\end{array}$ \\
\hline NCEP2 forecast and & & & \\
$\quad$ ERA-15/ECT forecast & 0.85 & 0.79 & 0.82 \\
NCEP2 forecast and DRM & 0.77 & 0.62 & 0.65 \\
$\begin{array}{l}\text { ERA-15/ECT forecast and } \\
\text { DRM }\end{array}$ & 0.89 & 0.72 & 0.71 \\
\hline
\end{tabular}

(SOI < 0) during 1982/83, 1986/87, and 1997/98. There is also an extended warm event beginning in 1991 with varying intensity through 1995. Each of the modeled precipitation series exhibit similar relationships with the SOI. For the approximate periods 1979-83 and 199099 , modeled precipitation and the SOI appear negatively correlated in Fig. 7a, with increases in the SOI matched by decreases in modeled precipitation. During the years 1983-90, on the other hand, the correspondence between the modeled precipitation and the SOI is less clear. It should be noted that the quality of ERA-15 near Antarctica is reduced due to surface height errors in the input of Antarctic observations, and this can impact the precipitation fields (Bromwich et al. 2000). There are analogous errors in the input of observations for the NCEP-National Center for Atmospheric Research (NCAR) reanalysis (Marshall 2002). Therefore, it is not surprising to find some disagreement between the different analyses. One time period when differences are apparent is during the late 1980s. All three estimates of West Antarctic precipitation shown in Fig. 7a indicate that minima occur during the El Niño event near 1987. This is more clearly seen in Fig. 5b. During the La Niña event that follows, the DRM displays a strong maximum in precipitation. Well-defined maxima, however, are not apparent during this La Niña in Fig. 7a for the forecast precipitation from ERA-15 and NCEP2. We shall discuss this event again later in this section.

To assess the relative strength of the ENSO teleconnection with West Antarctic precipitation, correlation analyses are performed for 1980-89, 1990-99, and 

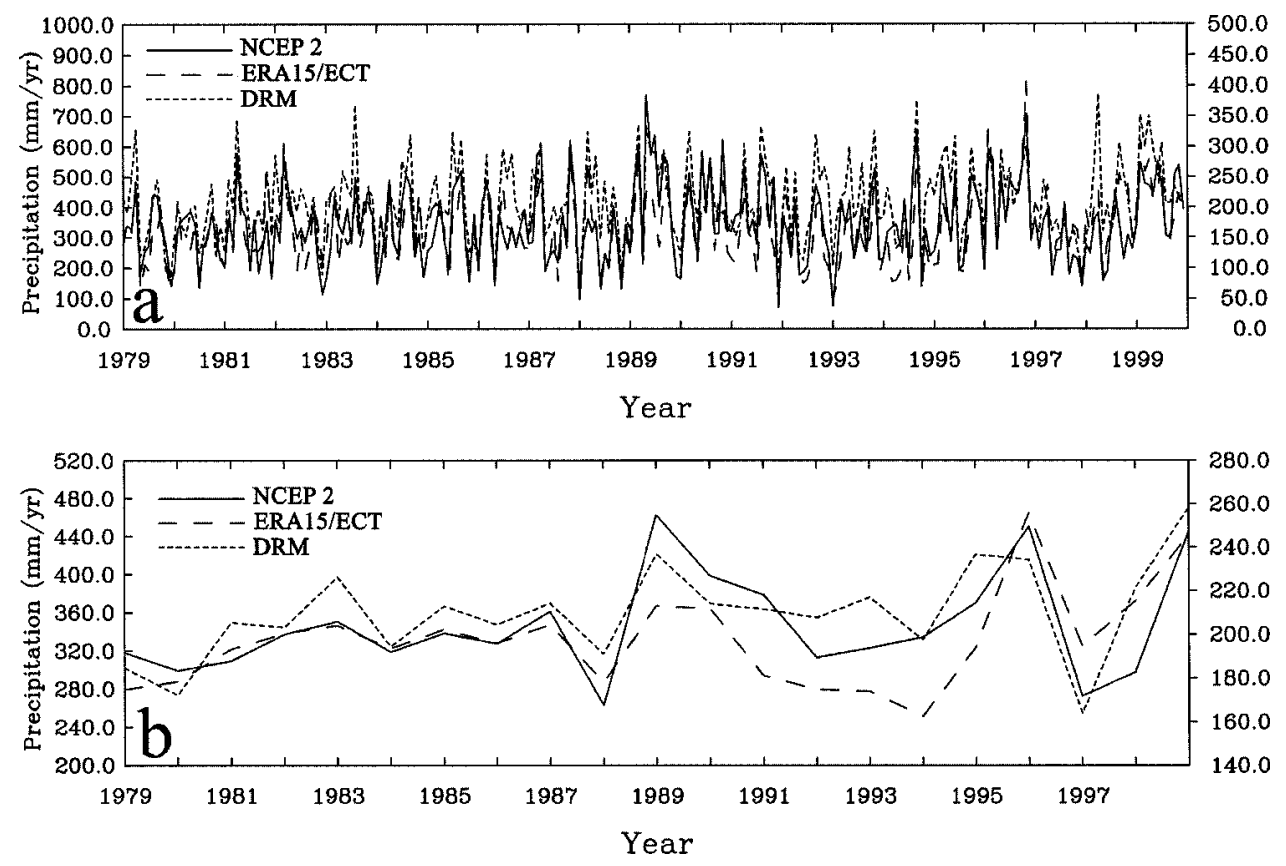

FIG. 6. Time series of the modeled precipitation for (a) monthly means and (b) annual means over the South Atlantic sector bounded by $65^{\circ}-75^{\circ} \mathrm{S}, 30^{\circ}-60^{\circ} \mathrm{W}$. Note that the right-hand scale is for DRM.

1979-99. Correlations between the SOI and West Antarctic precipitation calculated from three datasets are listed in Table 2. For the entire period under study, West Antarctic precipitation appears to be weakly anticorrelated with the SOI. This negative correlation, however, is found to be robust in 1990s. According to the $t$ test, if 10 years of data represent 10 independent samples, then correlations must be above 0.63 or 0.77 to be significant at the $95 \%$ and $99 \%$ confidence level, respectively. In the 1990s, correlations calculated from all three datasets are significant at the $95 \%$ confidence level.

Strong support for the decadally varying ENSO signal depicted in Fig. 7a is provided by a deuterium isotope time series (Fig. 7b). The time series is from a coastal ice core drilled at Siple Dome in the middle of the West Antarctic sector shown in Fig. 1. Kreutz et al. (2000) concluded from an analysis of a glaciochemical record from a Siple Dome ice core that ENSO variability has influenced this site for at least the past century. Deuterium isotope concentrations are a proxy for the net accumulation on the annual time scale in this area (Bromwich et al. 2000). Figure 7b compares the deuterium isotope concentrations with modeled precipitation in this area. The isotope time series appears to be anticorrelated to the SOI in earlier and later years of the period from 1979 to 1994 . Figure $7 b$, however, also shows an apparent positive correlation between the SOI and the isotope time series during the middle and late 1980s. The isotope record in the late 1980s includes a minimum followed by a large maximum, consistent with the DRM curve in Fig. 7a. Thus, it supports the findings of Bromwich et al. (2000). It is noted that these results are from one ice core, and additional cores drilled in this area would be helpful to confirm these results. Also, further verification is desirable to confirm that the variations in isotopic concentrations of deuterium are a good proxy for variations of precipitation in this area.

Cullather et al. (1996) and Bromwich et al. (2000) used the moisture flux budget (MFB) calculated from ERA-15 and ECT datasets to estimate accumulation for annual means. Figure 8 shows the computed 12-month centered running mean moisture convergence for both ERA-15 and ECT in comparison with the SOI. It is similar to an analysis by Bromwich et al. (2000); however, the ECT data is updated through the end of 1999. They conclude that the derived accumulation is positively correlated with the SOI from the early 1980s to 1990 and then switches abruptly to become strongly anticorrelated after 1990.

\section{c. Mechanisms for decadal differences}

A review of Figs. $7 \mathrm{a}$ and 8 and Table 2, however, shows conflicting evidence concerning the existence of a positive correlation during the 1980 s. Statistically significant positive correlations are not found for either the NCEP2 forecast precipitation or the ERA-15 forecast precipitation. The correlation for 1985-89 is significant for DRM using ERA-15. The large variation in the correlation for these years in Table 2 is indicative of the uncertainty. This is especially reflected in the differing response for the 1988/89 La Niña event seen in Figs. $7 \mathrm{a}$ and 8. 

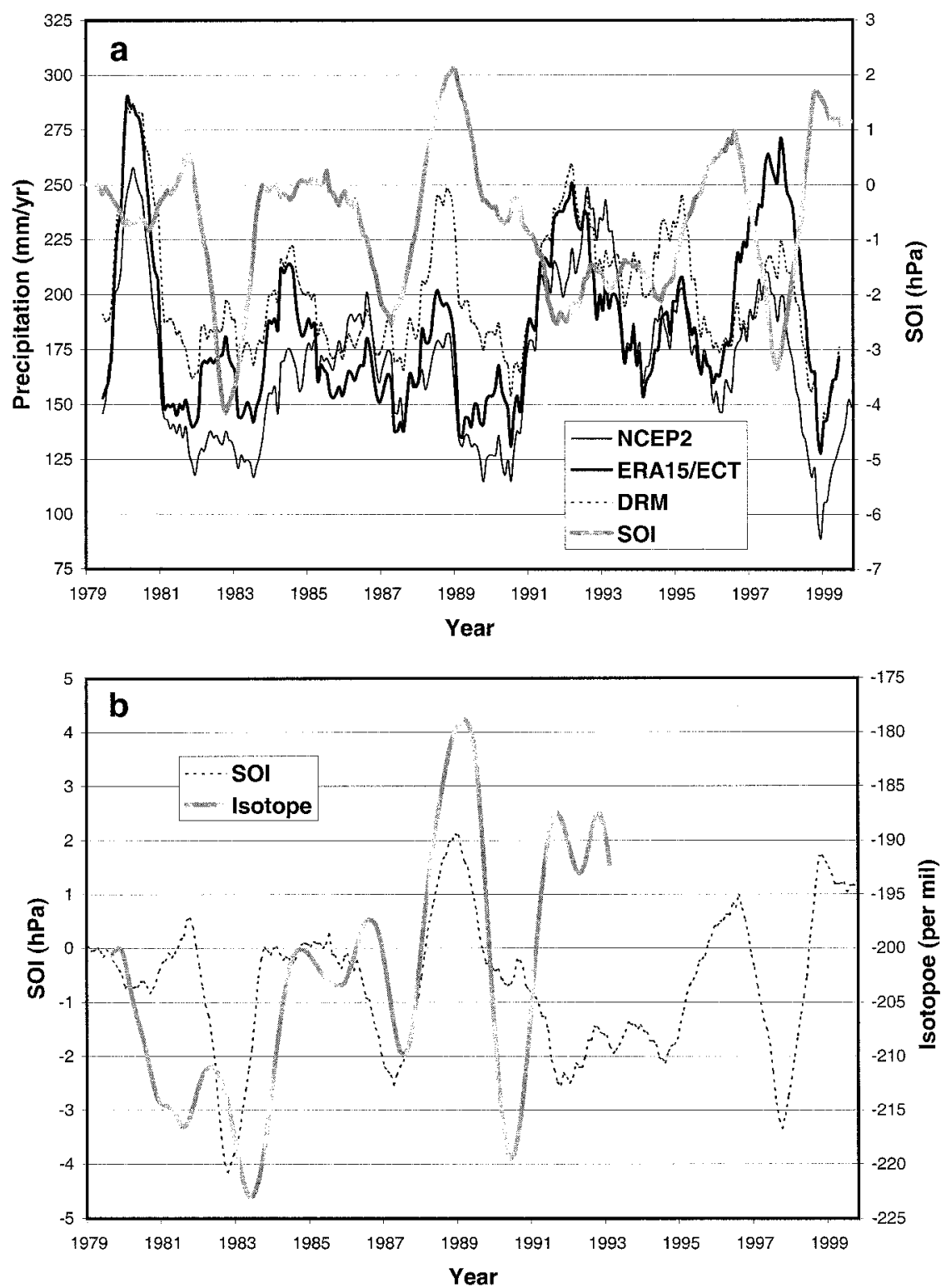

FIG. 7. The 12-month centered running means of the SOI and (a) modeled precipitation over the West Antarctic sector bounded by $75^{\circ}-90^{\circ} \mathrm{S}, 120^{\circ} \mathrm{W}-180^{\circ}$, and (b) deuterium isotope depletions obtained from Siple Dome ice core (after Bromwich et al. 2000).

TABLE 2. Correlation between the SOI and 12-month centered running mean of modeled precipitation over the West Antarctic sector bounded by $75^{\circ}-90^{\circ} \mathrm{S}, 120^{\circ} \mathrm{W}-180^{\circ}$.

\begin{tabular}{lcccc}
\hline \hline Modeled precipitation & $1979-99$ & $1979-89$ & $1990 / 91-99$ & $1985-89$ \\
\hline NCEP2 forecast & -0.31 & 0.22 & -0.75 & -0.08 \\
ERA-15 forecast & & 0.13 & & 0.44 \\
ECT forecast & & & -0.66 & \\
ERA-15/ECT forecast & -0.28 & & & 0.74 \\
DRM with ERA-15 & & 0.27 & -0.63 & \\
DRM with ERA-15/ECT & -0.10 & & - & \\
\hline
\end{tabular}

Insight into the variable impact of ENSO on West Antarctica is demonstrated by Fig. 9 that shows the average mean sea level pressure difference between La Niña events and El Niño events after 1979 and the anomaly patterns for ENSO events in the 1990s and late 1980s. The El Niño events selected for the difference pattern in Fig. 9a are 1982/83, 1987, 1991-95, and 1997/ 98. The La Niña events are 1988/89 and 1998/99. For the 1987 event, which actually began in late 1986 and ended in early 1988, a 12-month average from January to December is taken. All the other events are averaged from July to June. For the difference pattern in Fig. 9a the four El Niño events are each weighted by 0.25 and 


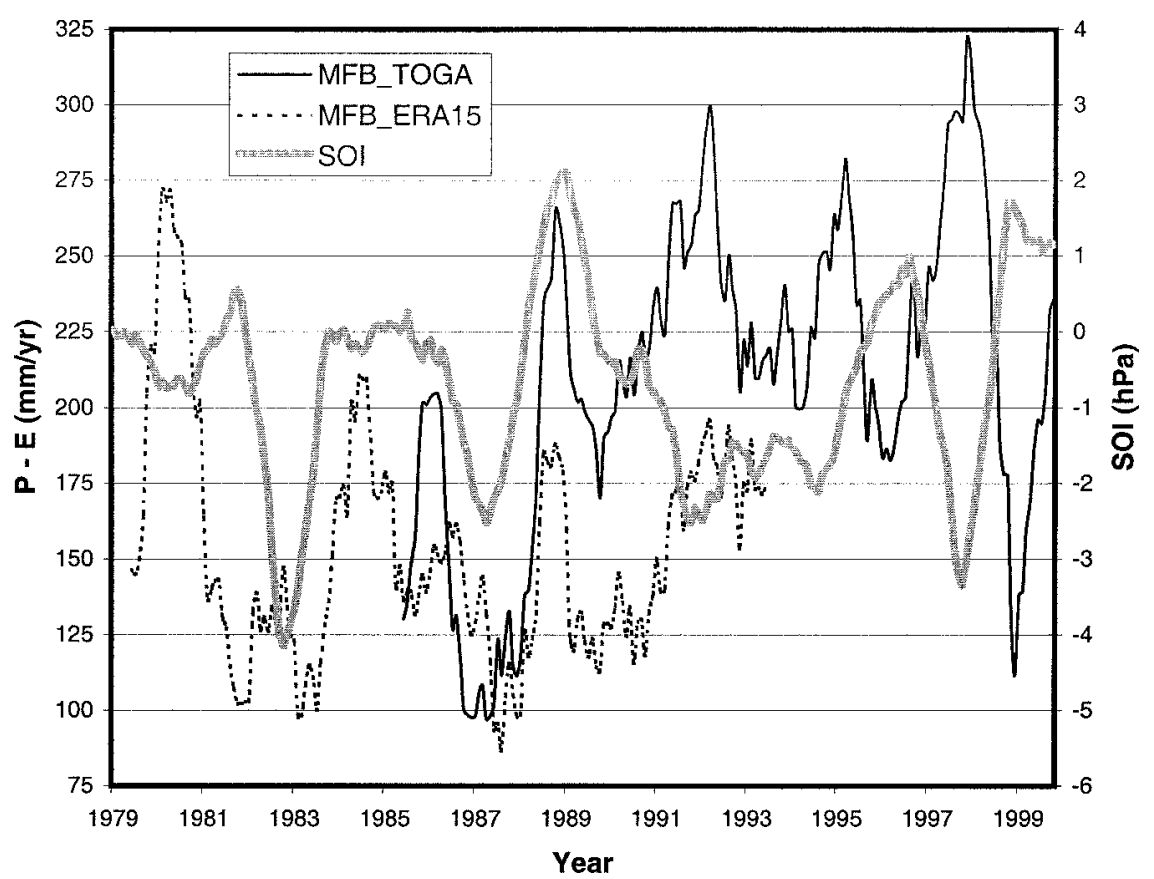

FIG. 8. The 12-month centered running means of the SOI and moisture flux convergence for the West Antarctic sector calculated from ERA-15 and ECT (after Bromwich et al. 2000).

the La Niña events are each weighted by 0.5 . The ERA15 reanalysis is used for fields from 1979 to 1990 , and ECT is used for 1991-99. Anomaly fields in Figs. 9b9f show the difference from the 1979-99 average.

The La Niña minus El Niño pattern in Fig. 9a is consistent with the weak overall negative correlation between the SOI and accumulation in the West Antarctic sector. As the geostrophic flow is clockwise around a low pressure center in the Southern Hemisphere, weak offshore flow occurs on the average during a La Niña event. In Fig. 9f (Figs. 9d and 9e) for the 1990s, however, the offshore (onshore) flow is stronger during La Niña (El Niño) events; hence the correlation is stronger. On the other hand, the 1980s events have important differences from the mean ENSO pattern in Fig. 9a. The reduced accumulation during the $1987 \mathrm{El}$ Niño is easily attributed to offshore geostrophic flow (Fig. 9b). While Fig. 9 reflects the variable response to ENSO in high latitudes, the 1987 event appears to be particularly anomalous. The anomalous accumulation during the 1988/89 La Niña is not apparent from Fig. 9c, as the geostrophic flow appears to be parallel to the West Antarctic shore west of $100^{\circ} \mathrm{W}$. Thus, perhaps it is not surprising that Figs. 7 and 8 display different accumulation characteristics for this event.

The NCEP2 forecast precipitation in Fig. 7a shows the weakest maximum for the 1988/89 La Niña. The NCEP2 value, however, may be unreliable near that time. Figure 10 shows the 12-month running mean of sea level pressure and 500-hPa geopotential height observed near the Pacific Antarctic coast at Leningradskaya $\left(69.5^{\circ} \mathrm{S}, 159.4^{\circ} \mathrm{E}\right)$ along with interpolated values from NCEP2, ERA-15, and ECT. The NCEP values show an apparently spurious drop of $3-4 \mathrm{hPa}$ in sea level pressure and 30-40 gpm in 500-hPa height during 1988. No similar trends are seen for ERA-15 and ECT, although Genthon (2002) notes that there appear to be surface height errors in the incorporation of Dome-C $\left(74.5^{\circ} \mathrm{S}, 123.0^{\circ} \mathrm{E}\right)$ data into ERA-15 around 1990 . The change in the NCEP2 fields near Leningradskaya suggests a station height error analogous to those at other sites found by Marshall (2002) for the NCEP-NCAR reanalysis during the 1990s and by Bromwich et al. (2000) for ERA-15. Cullather et al. (1997) also noticed that some of the largest biases versus observations for the ECMWF and NCEP operational analyses are found at Leningradskaya, where there may have been difficulties incorporating the observations into the analyses. Therefore, the variations of NCEP2 fields are suspect near the 1988/89 event, and the ERA-15 and ECT values appear to be preferable for this time period in the Pacific Antarctic region. The ERA-15 forecast precipitation does not show a statistically significant positive correlation as the 1988/89 maximum is weak compared to the early 1990s and 1997/98 maximum in Fig. 7a. On the other hand, the DRM using ERA-15 values for 1979-90 shows a strong maximum in accumulation for the 1988/89 La Niña and the positive correlation to the SOI during 1985-89 is statistically significant. The moisture flux calculations in Fig. 8 also show a strong accumulation maximum during $1988 / 89$ based on ECT. Given the support provided by the isotope values in Fig. $7 \mathrm{~b}$, it appears that the weight of reliable evidence sup- 

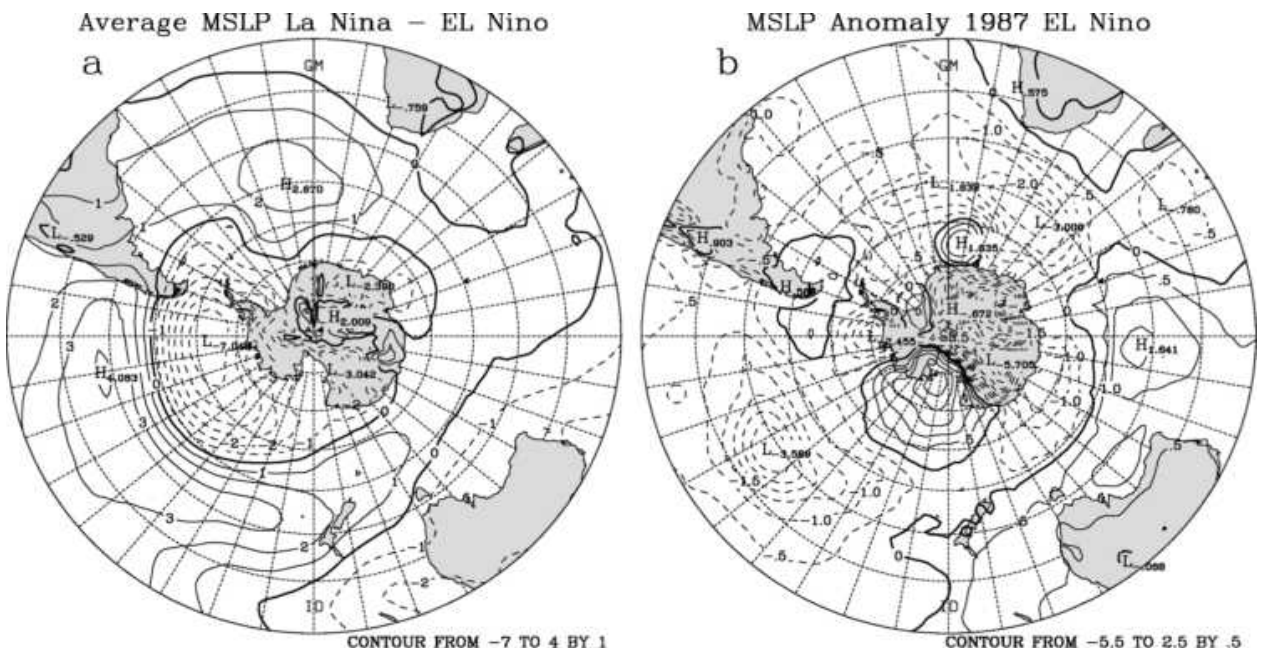

MSLP Anomaly 1988/89 La Nina

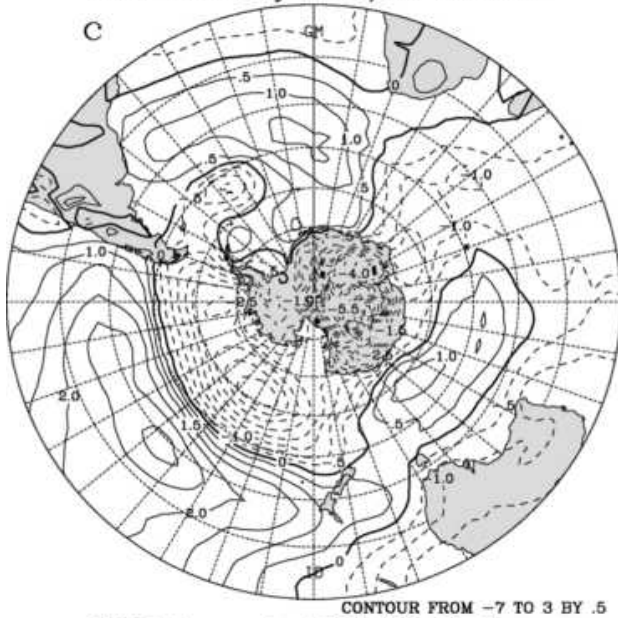

MSLP Anomaly 1991/95 El Nino

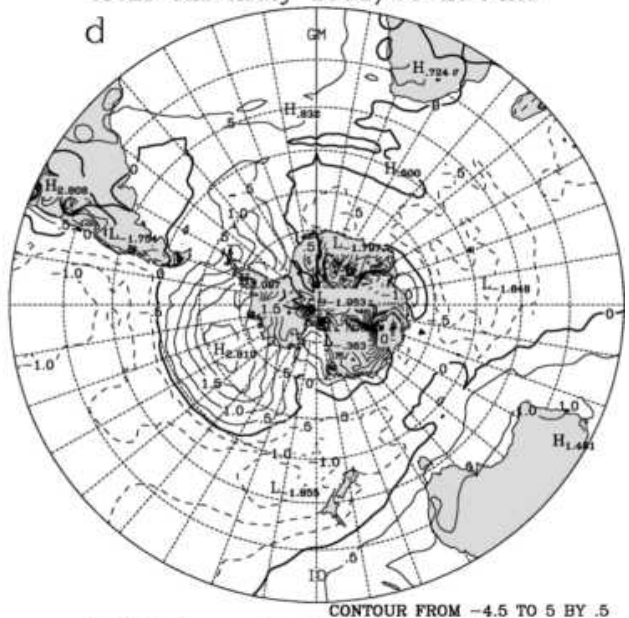

MSLP Anomaly 1997/98 El Nino
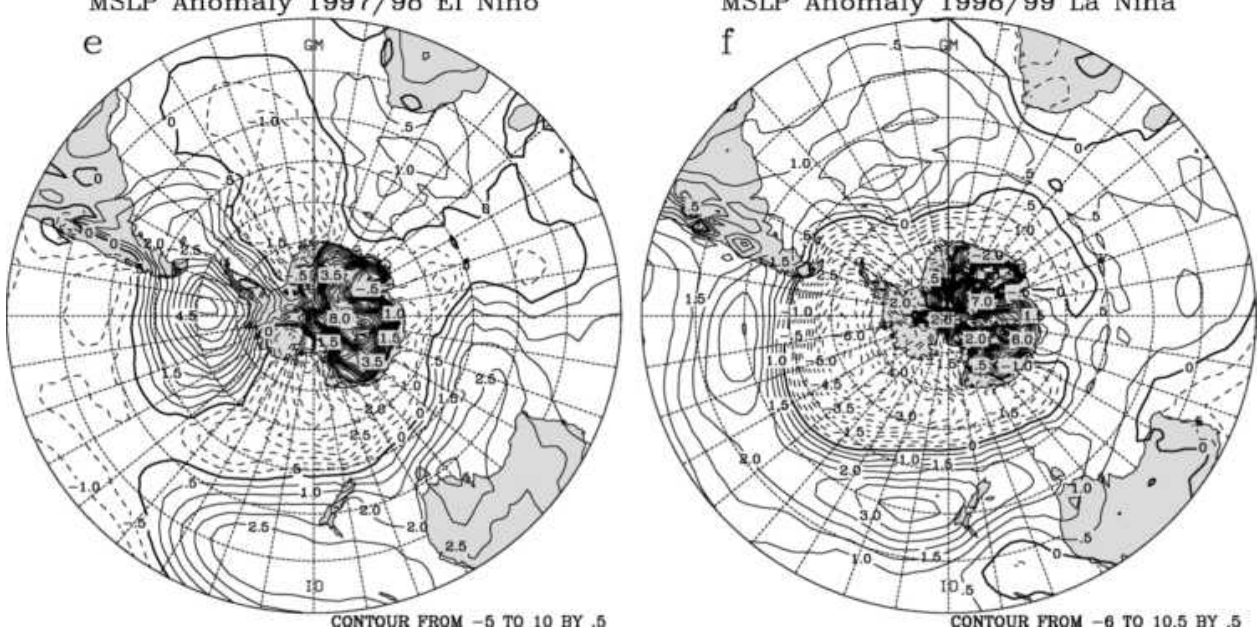

FIG. 9. Mean sea level pressure (hPa) differences between (a) averages of La Niña events and El Niño events, and between (b) the 1987 El Niño, (c) the 1988/89 La Niña, (d) the 1991-95 El Niño, (e) the 1997/ 98 El Niño, (f) the 1998/99 La Niña, and the 1979-99 annual mean. Contour interval is $1 \mathrm{hPa}$ in (a) and $0.5 \mathrm{hPa}$ in (b)-(f). Thick contour is 0 . 

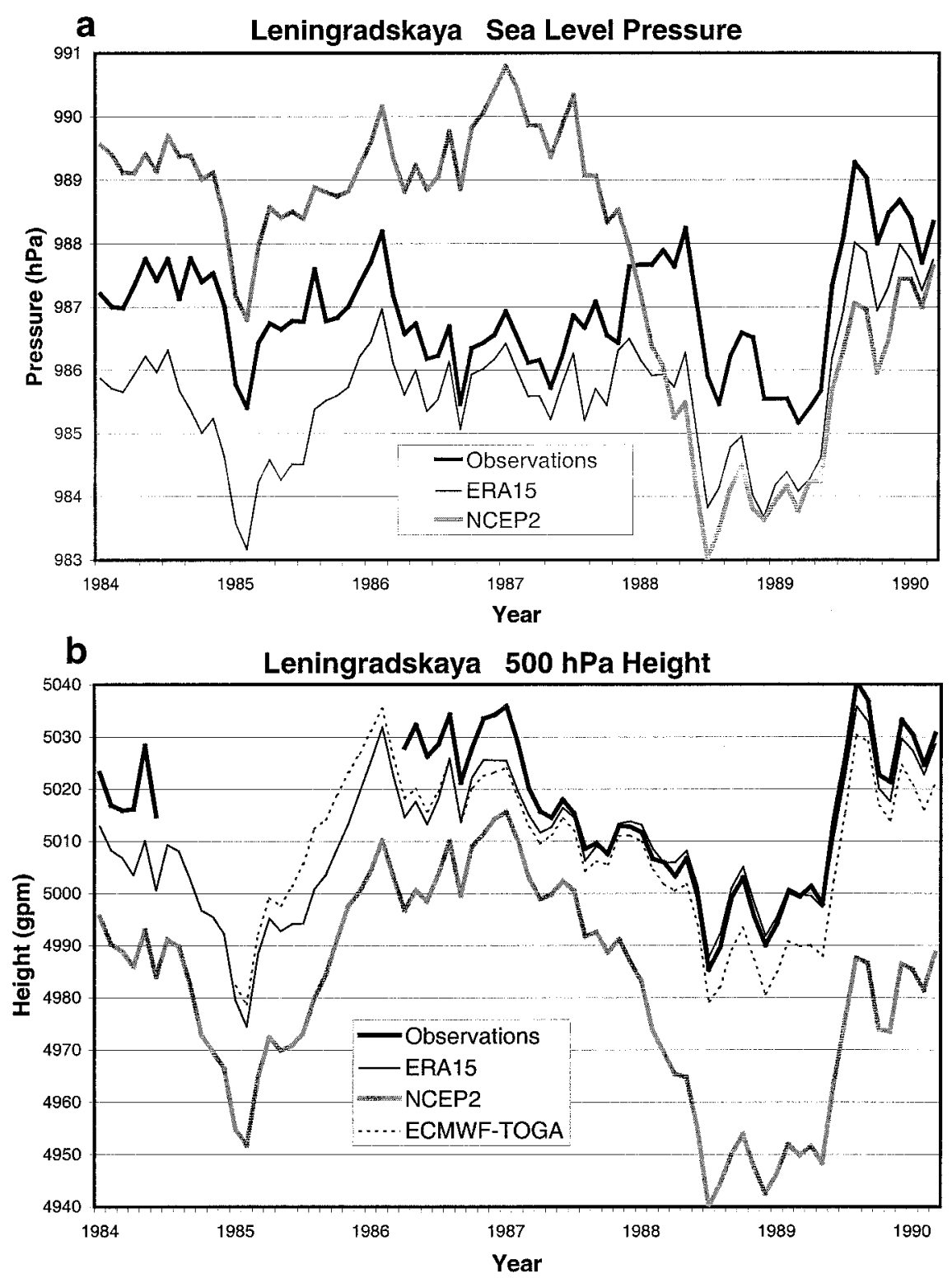

FIG. 10. The 12-month centered running means of (a) sea level pressure (hPa) and (b) 500-hPa geopotential height (gpm) for Leningradskaya observations, NCEP2, ERA-15, and ECT.

ports the positive correlation between West Antarctic accumulation and SOI during the middle and late 1980s.

While strong decadal variability is evident in the impact of ENSO on the West Antarctic precipitation with the relationship being much better defined in the 1990s than the 1980s, strong correlations can also be found between the SOI and other atmospheric variables. As an example, Fig. 11 shows the correlations between SOI and mean sea level pressure calculated from NCEP2 for the sets of years 1980-89, and 1990-99. The correlations between the SOI and mean sea level pressure are weak over the South Pacific-South American sector during the 1980s (Fig. 11a). While the 1990-99 pattern shows qualitative similarity to that during $1980-89$, the correlated regions are larger and show stronger statistical significance during the more recent decade (Fig. 11b). The regions of highest correlation have shifted eastward during the 1990s. The implied latitudinal advections of sea ice in the Weddell Sea and northeast of the Ross Sea as suggested by Fig. 11b are consistent with the Antarctic dipole, which is the seesaw relationship between sea ice extent in these basins modulated by the ENSO cycle (Yuan and Martinson 2001). Thus, the decadal variations in the ENSO teleconnection may have a signal in Antarctic sea ice.

Genthon and Krinner (1998) are unable to find a strong ENSO signal in the modeled West Antarctic precipitation using forecast precipitation from the ERA-15. 

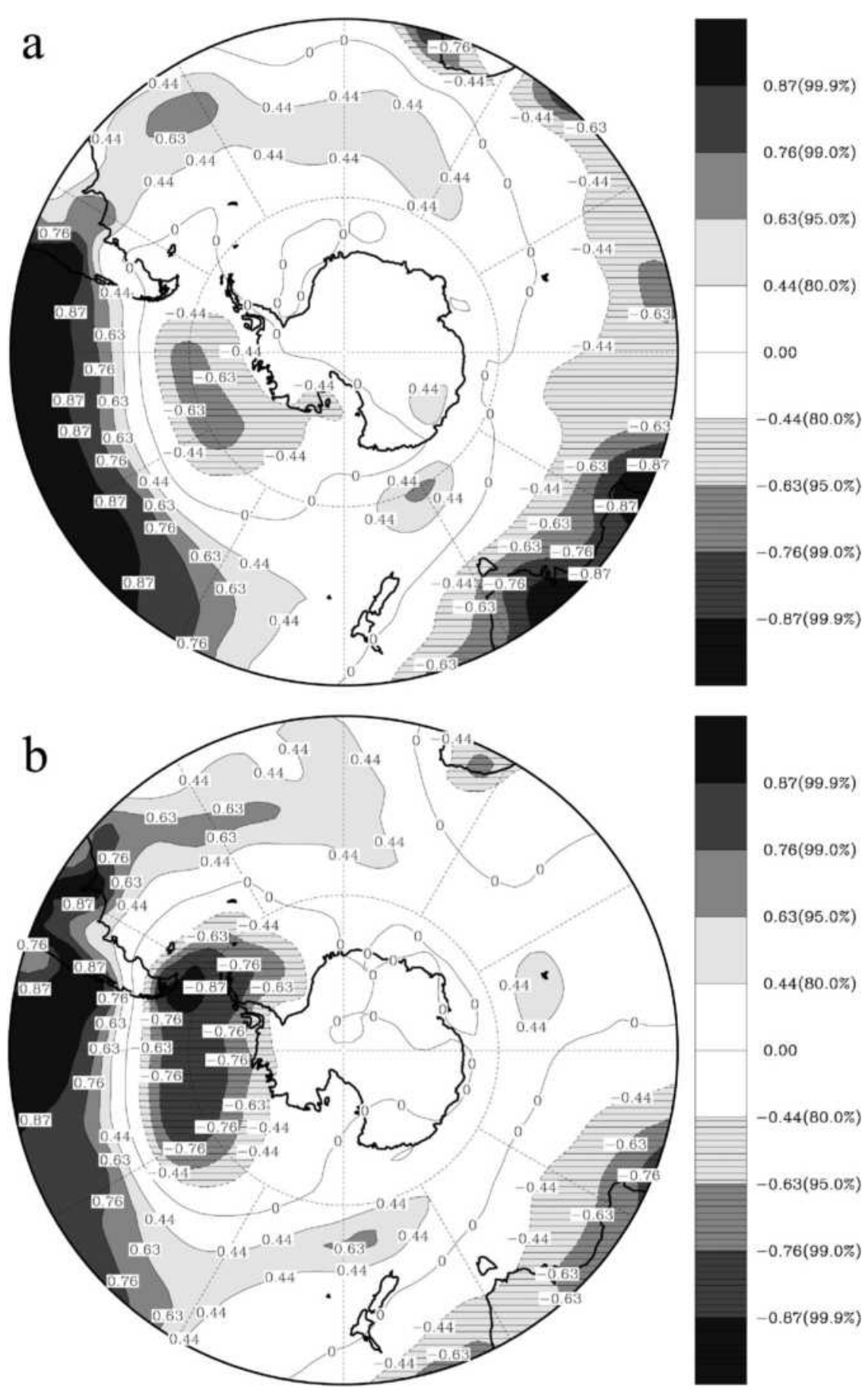

FIG. 11. Correlations of annual running mean of NCEP2 sea level pressure with the SOI for (a) 1980-89 and (b) 1990-99.

Bromwich et al. (2000) show that certain deficiencies exist in ERA-15, and these deficiencies result in a weaker ENSO signal in Antarctic precipitation. Furthermore, with only a few years of data, the anomalies in precipitation depend heavily on the mean field, and correlations are not optimal in bringing out such relationships (Trenberth and Caron 2000). Given the close relation- ship between mean circulation and interannual variability in precipitation, decadal changes present in impacts of the ENSO on mean circulation over the West Antarctic may affect ENSO signal detection in this area when only two decades of data are used.

Over the South Atlantic sector, a positive correlation is found between the area-averaged precipitation and 

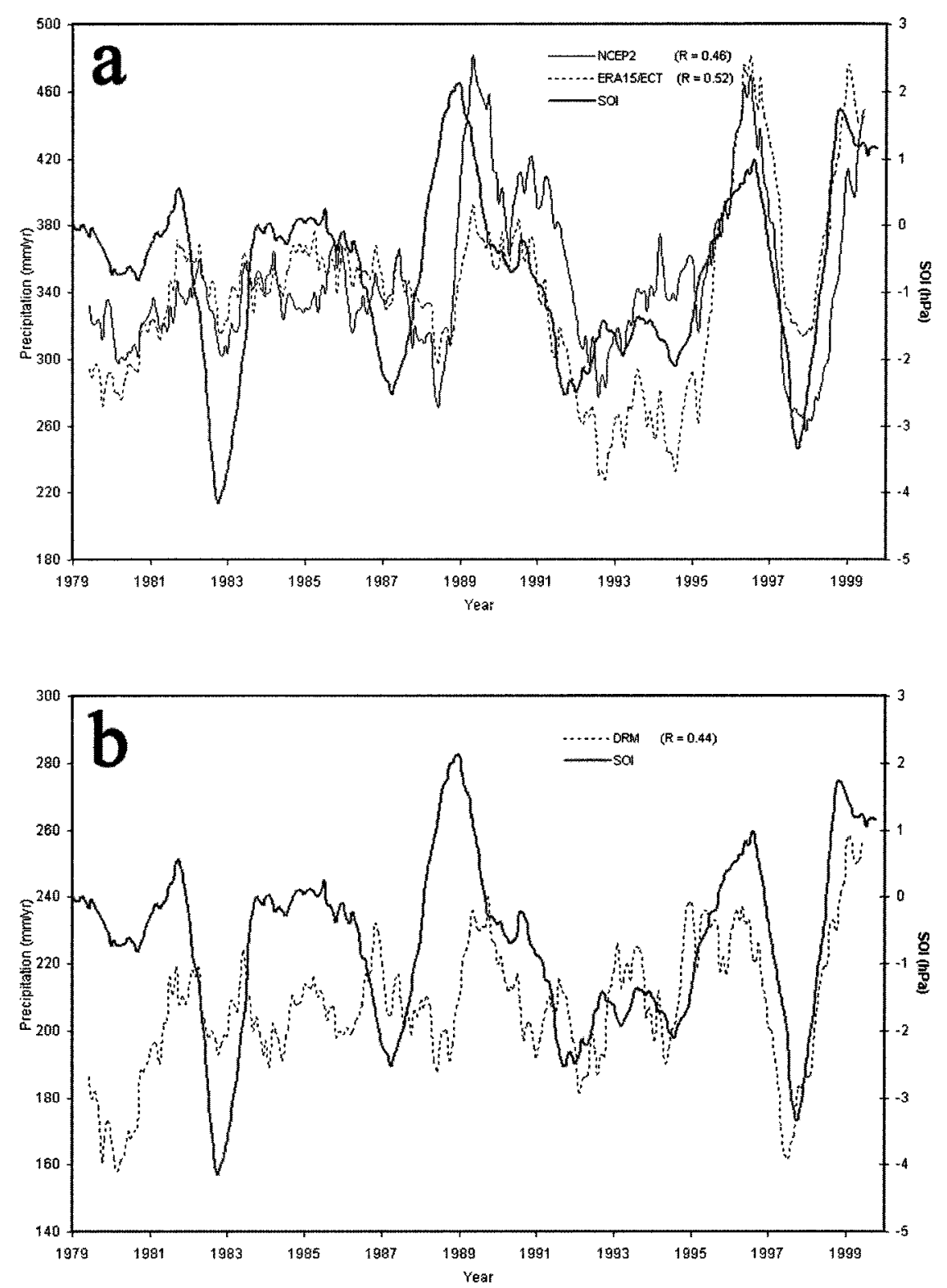

FIG. 12. The 12-month centered running means of the SOI and modeled precipitation over the South Atlantic sector bounded by $65^{\circ}-75^{\circ} \mathrm{S}, 30^{\circ}-60^{\circ} \mathrm{W}$ for (a) NCEP2 and ERA-15/ECT, and (b) DRM.

the SOI for the last two decades. Figure 12 presents the 12-month centered running mean modeled precipitation for the South Atlantic sector and the SOI. It shows that each of the modeled precipitation series exhibit similar correlation characteristics with the SOI. Overall, modeled precipitation and the SOI are positively correlated from 1979 to 1999, with increases (decreases) in the SOI matched by increases (decreases) in modeled precipitation. There does appear to be some linkage in Fig. 12 between the SOI and the modeled precipitation over the South Atlantic sector during the middle and late 1980s, perhaps with the modeled precipitation lagging the SOI. Unlike the case for the West Antarctic sector, there is not an obvious switch between negative and positive correlations, although the relationship appears better defined during the 1990s when significant sea level pressure correlations extend eastward into the Weddell Sea (Fig. 11b). According to a Student's $t$ test, the overall positive correlations between the SOI and precipitation over the South Atlantic sector from all three datasets are statistically significant at $95 \%$ confidence level for the last two decades.

In summary, there are small areas over the West Antarctic sector that show statistically significant negative correlations between the SOI and modeled precipitation for the last two decades. When averaged over the West 


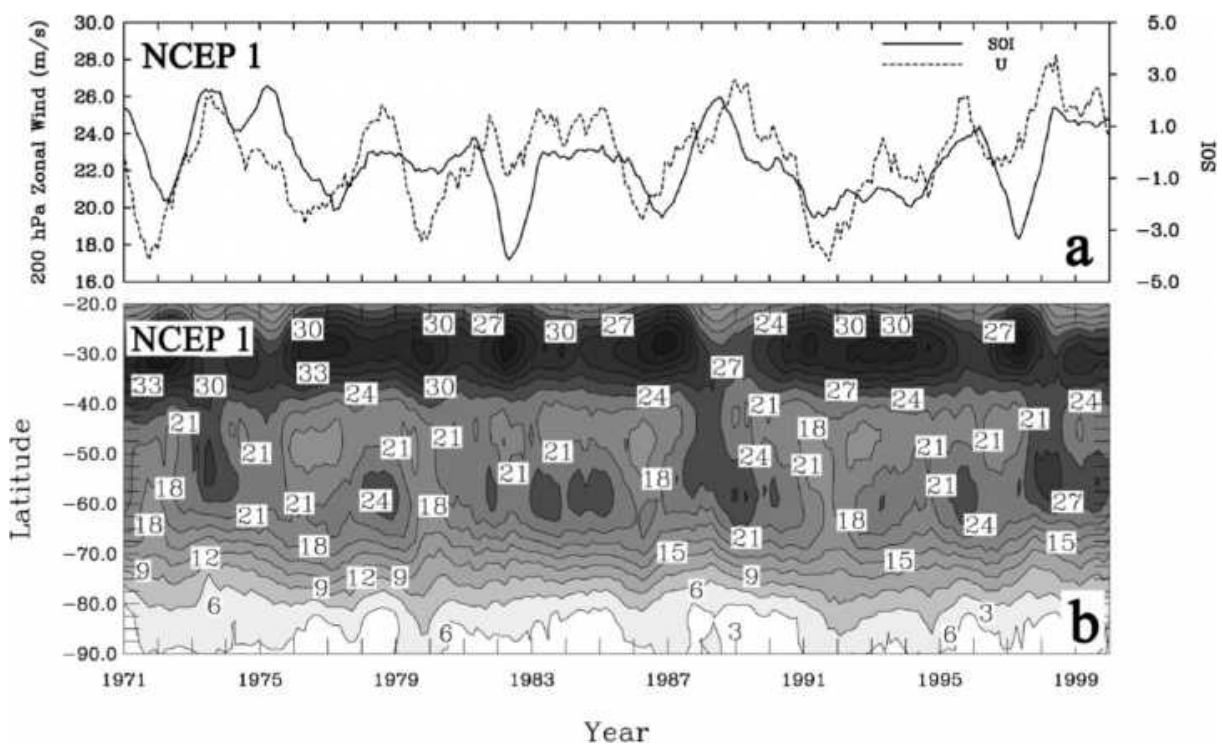

FIG. 13. The 12-month running means of (a) the SOI and 200-hPa zonal wind $\left(\mathrm{m} \mathrm{s}^{-1}\right)$ from the NCEPNCAR reanalysis averaged over the South Pacific sector bounded by $55^{\circ}-60^{\circ} \mathrm{S}, 120^{\circ} \mathrm{W}-180^{\circ}$ and (b) the zonal wind speed averaged over $120^{\circ} \mathrm{W}-180^{\circ}$. Calendar years are plotted at the midpoint of each year.

Antarctic sector, the correlation is not significant for 1979-99 due to the decadal-scale change that resulted in an apparent reversed correlation during the middle and late 1980s. The negative correlations, however, are robust during the 1990s.

\section{The linkage between the polar front jet and West Antarctic precipitation}

The West Antarctic sector is directly south of the domain of the South Pacific split jet. Previous studies find that cyclonic activity over this sector is influenced by the oscillatory strengthening and weakening of the subtropical and polar front jets associated with ENSO (Karoly 1989; Chen et al. 1996). Furthermore, disproportionately large amounts of precipitation occur over West Antarctica (Lettau 1969; Bromwich et al. 1995), where cyclonic activity is able to penetrate inland. These findings suggest that the polar front jet variability is connected with the ENSO variability of West Antarctic precipitation. Therefore, this section presents the ENSO modulation of the polar front jet along with the correlation between West Antarctic precipitation and polar front jet strength. Given that polar front jet strength is modulated by the ENSO cycle, when and if there is a strong correlation between the West Antarctic precipitation and the polar front jet strength, there could be a favored ENSO signal in West Antarctic precipitation.

\section{a. Polar front jet modulation by the ENSO cycle}

The ENSO cycle modulates the South Pacific jet streams with the intensity of the subtropical jet near $30^{\circ} \mathrm{S}$ anticorrelated to that of the polar front jet near $60^{\circ} \mathrm{S}$. This is noted by Chen et al. (1996) who show that, over the central South Pacific Ocean, the subtropical jet strengthens during El Niño events, while the polar front jet strengthens during La Niña events. The linkage with the polar front jet will now be demonstrated.

For analyzed fields prior to 1979 , the NCEP-NCAR reanalysis (Kalnay et al. 1996; Kistler et al. 2001) can be used, although some caution must be applied for climate studies near Antarctica (e.g., Marshall 2002). Figure 13 shows the annual running mean SOI and 200$\mathrm{hPa}$ zonal wind from NCEP-NCAR reanalysis (19682000) averaged over the South Pacific sector bounded by $55^{\circ}-60^{\circ} \mathrm{S}, 120^{\circ} \mathrm{W}-180^{\circ}$ for $1971-2000$. The NCEPNCAR reanalysis was impacted by an improper incorporation of the Southern Hemisphere Australian surface pressure bogus data (PAOBS; Kanamitsu et al. 2002). This error can significantly impact the day-to-day variability, but the monthly mean fields used here are not believed to be significantly degraded. There is also a spurious long-term increase in the wind speed for these latitudes (Hines et al. 2000). Figure 13, however, suggests that the SOI and the zonal wind interact primarily on a time scale of a few years. Thus, the spurious longterm trend is unlikely to adversely impact the correlation between the zonal wind and the SOI. The correlation between the two time series in Fig. 13a is 0.47. According to a Student's $t$ test, the correlation is significant at about the $99 \%$ confidence level. Figure $13 \mathrm{~b}$ shows the meridional distribution of the $200-\mathrm{hPa}$ zonal wind averaged over $120^{\circ} \mathrm{W}-180^{\circ}$; a clear relationship between the phase of the Southern Oscillation and the strength of polar front jet is apparent. The polar front jet tends to intensify during La Niña events and weaken during 
TABLE 3. Correlation of 12-month centered running means of the SOI and the 200-hPa zonal wind averaged over the South Pacific sector bounded by $55^{\circ}-60^{\circ} \mathrm{S}, 120^{\circ} \mathrm{W}-180^{\circ}$.

\begin{tabular}{lccccc}
\hline \hline \multicolumn{1}{c}{ Model } & $1971-2000$ & $1979-99$ & $1970-79$ & $1980-89$ & $1990-99$ \\
\hline NCEP-NCAR & 0.47 & 0.54 & 0.57 & 0.43 & 0.69 \\
NCEP2 & & 0.56 & & 0.47 & 0.71 \\
ERA-15/ECT & & 0.50 & & 0.46 & 0.68 \\
\hline
\end{tabular}

El Niño events. A similar positive correlation can be shown between the intensity of the polar front jet and the SOI for the ERA-15/ECT and NCEP2 datasets (Table 3 ).

Chen et al. (1996) investigated the physical mechanisms for the ENSO modulation of the polar front through a case study for the 1986-89 cycle including a moderate El Niño followed by a strong La Niña. Their momentum budget analysis shows that polar front jet strength is affected by both poleward eddy momentum transport from low latitudes nearer the tropical sea surface temperature anomalies and equatorward eddy momentum transport from high latitudes. It might be particularly true for 1988 that the polar front jet strength is highly influenced by the enhanced momentum transport on planetary scales (Chen et al. 1996) from the high-latitude blocking anomalies during that year (Bromwich et al. 1993). It may explain the anomaly in the modulation of polar front jet strength by the ENSO cycle around the year 1988. Notice in Fig. 13a that the
TABLE 4. Correlation of 12-month centered running means of modeled precipitation over the West Antarctic sector bounded by $75^{\circ}$ $90^{\circ} \mathrm{S}, 120^{\circ} \mathrm{W}-180^{\circ}$ and the $200-\mathrm{hPa}$ zonal wind averaged over the South Pacific sector bounded by $55^{\circ}-60^{\circ} \mathrm{S}, 120^{\circ} \mathrm{W}-180^{\circ}$.

\begin{tabular}{lccc}
\hline \hline \multicolumn{1}{c}{ Model } & $1979-99$ & $1980-89$ & $1990 / 91-99$ \\
\hline NCEP2 & -0.75 & -0.44 & -0.83 \\
ERA-15/ECT & -0.55 & -0.31 & -0.58 \\
\hline
\end{tabular}

maximum in polar front jet speed lags the 1988 maximum in the SOI.

\section{b. Correlation between West Antarctic precipitation and strength of polar front jet}

Figure 14 shows the correlation between modeled precipitation for the West Antarctic sector and the 200$\mathrm{hPa}$ zonal wind for the South Pacific sector. The precipitation data are averaged over $75^{\circ}-90^{\circ} \mathrm{S}, 120^{\circ} \mathrm{W}-$ $180^{\circ}$, while the $200-\mathrm{hPa}$ zonal winds are averaged over the sector $55^{\circ}-60^{\circ} \mathrm{S}, 120^{\circ} \mathrm{W}-180^{\circ}$, where the polar front jet is centered. It clearly shows that there is an overall negative correlation between the West Antarctic precipitation and the 200-hPa zonal wind during the last two decades. The correlations are -0.75 and -0.55 for the NCEP2 and ERA-15/ECT datasets, respectively (Table 4). The values are significant at the $99 \%$ confidence level.

The connection between ENSO and the polar front
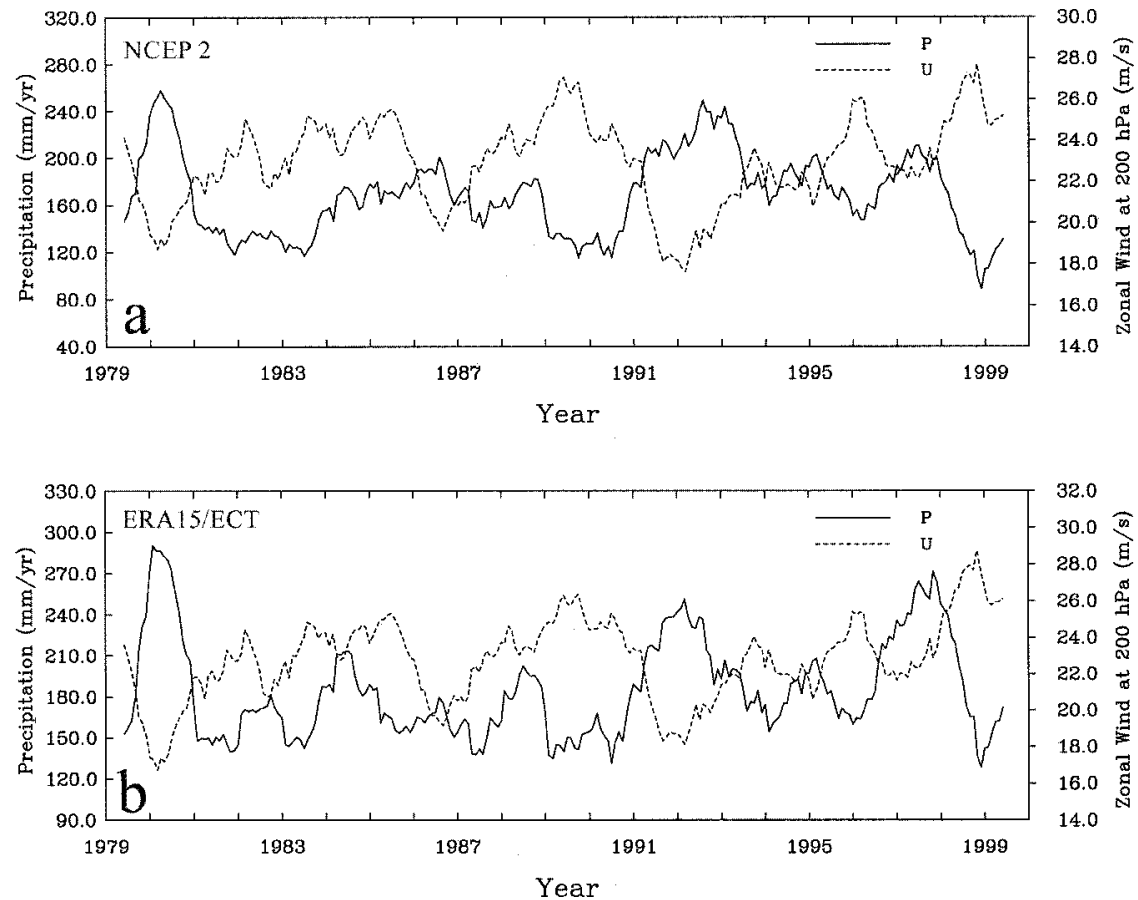

FIG. 14. Annual running means of modeled precipitation averaged over the West Antarctic sector bounded by $75^{\circ}-90^{\circ} \mathrm{S}, 120^{\circ} \mathrm{W}-180^{\circ}$ and $200-\mathrm{hPa}$ zonal wind averaged over the South Pacific sector bounded by $55^{\circ}-60^{\circ} \mathrm{S}, 120^{\circ} \mathrm{W}-180^{\circ}$ for (a) the NCEP-DOE AMIP-2 reanalysis and (b) the combined ERA-15 and ECT datasets, respectively. 
jet over the central and eastern Pacific Ocean in the Southern Hemisphere can be understood from the difference between the El Niño and La Niña pressure gradients implied by Figs. 9a and 11. During La Niña (El Niño) events, the midlatitude pressure gradient supports a stronger (weaker) polar front jet stream. Over the western Pacific Ocean, the connection between the pressure gradient and ENSO is less well defined; hence there is not a strong correlation between the polar front jet stream and ENSO there (Bals-Elsholz et al. 2001). As the ENSO response in the pressure field is better defined in the 1990s, especially over the eastern Pacific basin, the correlation to the polar front jet is also larger.

\section{Summary}

The ENSO signal in modeled precipitation is evaluated using several sources including the NCEP-DOE AMIP-2 reanalysis, a combination of the ECMWF 15yr Re-Analysis and the ECMWF/TOGA operational analysis, and the dynamic retrieval method. The use of multiple sources helps reduce impacts of errors in the individual datasets. Furthermore, the agreement between the results from the various sources provides some estimate of the reliability of the results. The sum of results in this study indicates that there is an overall anticorrelation between the SOI and precipitation over the West Antarctic sector bounded by $75^{\circ}-90^{\circ} \mathrm{S}, 120^{\circ} \mathrm{W}-$ $180^{\circ}$ during the years $1979-2000$, while the correlation is positive for the South Atlantic sector bounded by $65^{\circ}-$ $75^{\circ} \mathrm{S}, 30^{\circ}-60^{\circ} \mathrm{W}$. Furthermore, the polar front jet north of the West Antarctic sector is positively correlated to the SOI.

The negative correlation between the SOI and West Antarctic precipitation in the West Antarctic sector is particularly pronounced during the 1990s. During this decade, the ENSO teleconnection pattern in the eastern South Pacific region is better defined and shifted eastward compared to that of the 1980s. The quasi-stationary eddies north of West Antarctica appear to be responsible for the decadal variation of the teleconnection between ENSO and West Antarctic precipitation. These eddies establish onshore or offshore flow patterns bringing wet or dry conditions, respectively. During the 1990s, moisture advection by the quasi-stationary eddies supported the negative correlation to the SOI. The midlatitude pressure gradient associated with the eddies also influences the teleconnection between ENSO and the local polar front jet speed.

On the other hand, from about 1983 to 1989 the quasistationary eddies during ENSO extreme events apparently supported a positive correlation between the SOI and West Antarctic precipitation. As there is considerable variation between the different estimates of precipitation during this time period, the teleconnection between ENSO and West Antarctic precipitation is less certain. Nevertheless, the weight of evidence supports the positive correlation previously found by Cullather et al. (1996) and Bromwich et al. (2000). Future ice core studies on the West Antarctic ice sheet may help to clarify the decadal modulation of the ENSO signal. Additionally, the new multiyear reanalysis from ECMWF (ERA-40) for 1957 onward should provide a more reliable signal of ENSO in the Antarctic region. The ERA-40 benefits from the lessons learned during the earlier generation of reanalyses, and the Antarctic research community has had considerable input. Additional observations are incorporated into ERA-40, and elevation errors present in earlier analyses and reanalyses have been removed. The variable high-latitude response to the ENSO cycle demonstrated here encourages future research to explore the mechanisms responsible for the decadal changes.

Acknowledgments. This research was funded by National Science Foundation Grants OPP-9725730, OPP9707557, and OPP-9905381 to D. H. Bromwich. The global analyses and reanalyses used in this project were obtained from NCAR under Grant 3706880.

\section{REFERENCES}

Bals-Elsholz, T. M., E. H. Atallah, L. F. Bosart, T. A. Wasula, M. J. Cempa, and A. R. Lupo, 2001: The wintertime Southern Hemisphere split jet: Structure, variability, and evolution. J. Climate, 14, 4191-4215.

Bentley, C. R., 1993: Antarctic mass balance and sea level change. Eos, Trans. Amer. Geophys. Union, 74, 585-586.

Bromwich, D. H., J. F. Carrasco, Z. Liu, and R.-Y. Tzeng, 1993 Hemispheric atmospheric variations and oceanographic impacts associated with katabatic surges across the Ross Ice Shelf, Antarctica. J. Geophys. Res., 98, 13 045-13 062.

_ , F. M. Robasky, R. I. Cullather, and M. L. Van Woert, 1995: The atmospheric hydrologic cycle over the Southern Ocean and Antarctica from operational numerical analyses. Mon. Wea. Rev., 123, 3518-3538.

—, A. N. Rogers, P. Kållberg, R. I. Cullather, J. W. C. White, and K. J. Kreutz, 2000: ECMWF analyses and reanalyses depiction of ENSO signal in Antarctic precipitation. J. Climate, 13, 14061420

—, Q.-S. Chen, L.-S. Bai, E. N. Cassano, and Y.-F. Li, 2001: Modeled precipitation variability over the Greenland Ice Sheet. J. Geophys. Res., 106, 33 891-33908.

_ - Z.-C. Guo, L. Bai, and Q.-S. Chen, 2004a: Modeled Antarctic precipitation. Part I: Spatial and temporal variability. J. Climate, 17, 427-447.

_ A. J. Monaghan, and Z.-C. Guo, 2004b: Modeling the ENSO modulation of Antarctic climate in the late 1990s with the Polar MM5. J. Climate, 17, 109-132.

Carleton, A. M., 1988: Sea ice-atmosphere signal of the Southern Oscillation in the Weddell Sea, Antarctica. J. Climate, 1, 379388.

Chen, B., S. R. Smith, and D. H. Bromwich, 1996: Evolution of the tropospheric split jet over the South Pacific Ocean during the 1986-89 ENSO cycle. Mon. Wea. Rev., 124, 1711-1731.

Chen, Q.-S., D. H. Bromwich, and L. Bai, 1997: Precipitation over Greenland retrieved by a dynamic method and its relation to cyclonic activity. J. Climate, 10, 839-870.

Cullather, R. I., D. H. Bromwich, and M. L. Van Woert, 1996: Interannual variability in Antarctic precipitation related to El NiñoSouthern Oscillation. J. Geophys. Res., 101, 19 109-19 118. _ _ _ , and R. W. Grumbine, 1997: Validation of operational 
numerical analyses in Antarctic latitudes. J. Geophys. Res., 102, $13761-13784$.

Genthon, C., 2002: Climate and surface mass balance of the polar ice sheets in ERA40/ERA15. ERA-40 Project Report Series, Vol. 3 , European Centre for Medium-Range Weather Forecasts, 299-316. [Available online at http://www.ecmwf.int/publications/library/ ecpublications/proceedings/ERA40-reanalysis_workshop/genthon. pdf.]

_ , and G. Krinner, 1998: Convergence and disposal of energy and moisture on the Antarctic polar cap from ECMWF reanalyses and forecasts. J. Climate, 11, 1703-1716.

Gloersen, P., 1995: Modulation of hemispheric sea-ice cover by ENSO events. Nature, 373, 503-506.

Guo, Z., 2003: Spatial and temporal variability of modern Antarctic precipitation. Ph.D. dissertation, The Ohio State University, 150 pp.

, D. H. Bromwich, and J. J. Cassano, 2003: Evaluation of Polar MM5 simulations of Antarctic atmospheric circulation. Mon Wea. Rev., 131, 384-411.

Hansen, J., J. Ruedy, J. Glascoe, and M. Sato, 1999: GISS analysis of surface temperature change. J. Geophys. Res., 104, 30997 31022 .

Hines, K. M., and D. H. Bromwich, 2002: A pole to pole West Pacific atmospheric teleconnection during August. J. Geophys. Res. 107, 4359, doi:10.1029/2001JD001335.

— $-\ldots$, and G. J. Marshall, 2000: Artificial surface pressure trends in the NCEP/NCAR reanalysis over the Southern Ocean and Antarctica. J. Climate, 13, 3940-3952.

Huffman, G. J., and Coauthors, 1997: The Global Precipitation Climatology Project (GPCP) combined data set. Bull. Amer. Meteor. Soc., 78, 5-20.

Kalnay, E., and Coauthors, 1996: The NCEP/NCAR 40-Year Reanalysis Project. Bull. Amer. Meteor. Soc., 77, 437-471.

Kanamitsu, M., W. Ebisuzaki, J. Woollen, S.-K. Yang, J. J. Hnilo, M. Fiorino, and G. L. Potter, 2002: NCEP-DOE AMIP-II Reanalysis (R-2). Bull. Amer. Meteor. Soc., 83, 1631-1643.

Karoly, D. J., 1989: Southern Hemisphere circulation features associated with El Niño-Southern Oscillation events. J. Climate, 2, 1239-1252.

King, J. C., 1994: Recent climate variability in the vicinity of the Antarctic Peninsula. Int. J. Climatol., 14, 357-369.

Kistler, R., and Coauthors, 2001: The NCEP-NCAR 50-Year Reanalysis: Monthly means CD-ROM and documentation. Bull. Amer. Meteor. Soc., 82, 247-267.

Kreutz, K. J., P. A. Mayewski, I. I. Pittalwala, L. D. Meeker, M. S. Twickler, and S. I. Whitlow, 2000: Sea level pressure variability in the Amundsen Sea region inferred from a West Antarctic glaciochemical record. J. Geophys. Res., 105, 4047-4059.

Kwok, R., and J. C. Comiso, 2002: Southern Ocean climate and sea ice anomalies associated with the Southern Oscillation. J. Climate, 15, 487-501.

Lettau, B., 1969: The transport of moisture into the Antarctic interior Tellus, 21, 331-340.

Liu, H., K. C. Jezek, and B. Li, 1999: Development of an Antarctic digital elevation model by integrating cartographic and remotely sensed data: A geographic information system based approach. J. Geophys. Res., 104, 23 199-23 213.

Marshall, G. J., 2002: Trends in Antarctic geopotential height and temperature: A comparison between radiosonde and NCEPNCAR reanalysis data. J. Climate, 15, 3940-3952.

_ , and S. A. Harangozo, 2000: An appraisal of NCEP/NCAR reanalysis MSLP data viability for climate studies in the South Pacific. Geophys. Res. Lett., 27, 3057-3060.

Parish, T. R., and D. H. Bromwich, 1998: A case study of Antarctic katabatic wind interaction with large-scale forcing. Mon. Wea. Rev., 126, 199-209.

Rott, H., W. Rack, T. Nagler, and P. Skvarca, 1998: Climatically induced retreat and collapse of northern Larsen Ice Shelf, Antarctic Peninsula. Ann. Glaciol., 27, 86-92.

Scambos, T. A., C. Hulbe, M. Fahnestock, and J. Bohlander, 2000: The link between climate warming and break-up of ice shelves in the Antarctic Peninsula. J. Glaciol., 46, 516-530.

Simmonds, I., and T. H. Jacka, 1995: Relationships between the interannual variability of Antarctic sea ice and the Southern Oscillation. J. Climate, 8, 637-647.

Smith, R. C., S. E. Stammerjohn, and K. E. Baker, 1996: Surface air temperature variations in the western Antarctic Peninsula region. Foundations for Ecological Research West of the Antarctic Peninsula, R. M. Ross, E. E. Hofmann, and L. B. Quetin, Eds., Antarctic Research Series, Vol. 70, Amer. Geophys. Union, 105121

Smith, S. R., and C. R. Stearns, 1993: Antarctic pressure and temperature anomalies surrounding the minimum in the Southern Oscillation index. J. Geophys. Res., 98, 13 071-13 083.

Trenberth, K. E., and J. M. Caron, 2000: The Southern Oscillation revisited: Sea level pressure, surface temperatures, and precipitation. J. Climate, 13, 4358-4365.

Xie, P. P., and P. A. Arkin, 1998: Global monthly precipitation estimates from satellite-observed outgoing longwave radiation. $J$. Climate, 11, 137-164.

Yuan, X., and D. G. Martinson, 2000: Antarctic sea ice extent variability and its global connectivity. J. Climate, 13, 1697-1717. , and — 2001: The Antarctic dipole and its predictability. Geophys. Res. Lett., 28, 3609-3612. 